\title{
志留纪初宜昌上升及其周缘龙马溪组黑色笔石 页岩的圈层展布模式
}

陈旭 ${ }^{1,2^{*}}$ ，陈清 ${ }^{1}$, 甄勇毅 ${ }^{3}$ ，王红岩 ${ }^{4}$, 张琳娜 ${ }^{5}$, 张俊鹏 ${ }^{1}$ ，王文开 ${ }^{6}$, 肖朝晖 ${ }^{7}$

1. 中国科学院南京地质古生物研究所和生物演化与环境卓越中心, 资源地层学与古地理学重点实验室, 南京 210008 ;

2. 浙江省核工业部地质大队院士工作站, 湖州 313000;

3. Geological Survey of New South Wales, W. B. Clarke Geoscience Centre, Londonderry NSW 2753, Australia;

4. 中国石油勘探开发研究院, 廊坊 065007 ;

5. 中国科学院南京地质古生物研究所和生物演化与环境卓越中心, 现代古生物学和地层学国家重点实验室, 南京 210008 ;

6. 中南大学地球科学与信息物理学院, 长沙 410012;

7. 华电华中清洁能源有限公司, 武汉 430071

*E-mail: xuchen@nigpas.ac.cn

收稿日期：2017-12-19; 收修改稿日期：2018-03-22; 接受日期：2018-05-09; 网络版发表日期：2018-07-05 中国科学院战略性先导科技专项(B类)项目(编号: XDB26000000)、国家自然科学基金项目(批准号: U1562213和41502025)和国家科技重大专 项项目(编号: 2017ZX05035002-001)资助

摘要 渝东、鄂西和湘西北志留系兰多维列统鲁丹阶至埃隆阶下部的地层存在不同程度的缺失, 因此这一地区 性的抬升被称为宜昌上升. 本文通过丰富的剖面地层资料, 阐明了宜昌上升的时空分布模式. 由于与之相关的龙 马溪组底部黑色页岩的不同程度的缺失, 关系到对其中赋存的页岩气的勘探, 因此, 宜昌上升的分布模型对该地 区及其周缘页岩气的勘探开发布局有指导作用. 本文与 “黔渝地区志留系龙马溪组黑色页岩的阶段性渐进展布模 式”一文, 共同提供了中国中上扬子区奥陶-志留系之交黑色页岩地层的一个完整的分布模式.

关键词宜昌上升, 鲁丹阶, 埃隆阶, 笔石生物带, 圈层展布模式

\section{1 前言}

“宜昌上升”一名最初系由孙云铸教授(Sun，1943) 提出. 当时中国地质界普遍认为华南奥陶系与志留系 之间存在着一个沉积间断, 因此孙云铸就以宜昌上升 来解释奥陶系艾家山组与志留系富池组之间的“间 断”. 他把五峰页岩归入志留系, 代表志留纪海侵的开
始, 并认为产自五峰组中的笔石“Climacograptus supernus Elles et Wood”和“Climacograptus latus Elles et Wood”虽源出于欧洲的奥陶纪地层, 但在志留纪初 才迁移至华南. 此外, 孙云铸之所以用“宜昌”来命名此 上升, 可能是因为艾家山组的标准剖面位于宜昌市范 围之内的缘故.

由于孙云铸教授(Sun，1943)的文章是一篇论及中

\footnotetext{
中文引用格式: 陈旭, 陈清, 甄勇毅, 王红岩, 张琳娜, 张俊鹏, 王文卉, 肖朝晖. 2018. 志留纪初宜昌上升及其周缘龙马溪组黑色笔石页岩的圈层展布模式. 中国 科学: 地球科学, 48: 1198-1206, doi: 10.1360/N072017-00445

英文引用格式: Chen X, Chen Q, Zhen Y Y, Wang H Y, Zhang L N, Zhang J P, Wang W H, Xiao Z H. 2018. Circumjacent distribution pattern of the Lungmachian graptolitic black shale (early Silurian) on the Yichang Uplift and its peripheral region. Science China Earth Sciences, 61: 1195-1203, https://doi.org/ $10.1007 / \mathrm{s} 11430-017-9222-\mathrm{x}$
} 
国古生界各系界线划分原则的总结性论文，因此引起 了当时中国地质界的普遍关注. 但当时地质界的其他 几位代表性学者对此却持有不同看法，如尹赞勋、李 星学(1943) $)^{1)}$ 认为五峰组应属奥陶纪Ashgillian期, 尹赞 勋先生(1943)在论及龙马溪页岩时, 虽然将五峰组划 入龙马溪页岩底部, 但又表示各地五峰页岩的时代不 尽相同; 王钰先生(1945)表示五峰组的时代应属奥陶 纪, 而盛莘夫先生 (1941, 穆恩之先生面告)是最早明确 表示五峰组应属奥陶系的，可惜他的文稿迟迟没有发 表. 从上述情况可见, 在 20 世纪 40 年代中期, 准确地研 究五峰组的地层和所含的笔石动物群, 已成为当时研 究奥陶系与志留系之间关系的核心问题.

在这种情况下, $\mathrm{Mu}(1945) 、 \mathrm{Yin}$ 和 $\mathrm{Mu}(1945)$ 以及穆 恩之(1950)的论文应运而生. 他们陆续描述了五峰组 中重要的笔石属种, 明确了扬子区五峰组含笔石黑色 页岩的时代应属于奥陶纪末期. 随后, 穆恩之(1954)对 扬子区的五峰组进行了第一次总结，不仅再次确认了 五峰组的时代，同时又明确了尽管长江流域的大部分 地区，奥陶系与志留系之间是连续沉积的，但是在湘 (湖南临湘)鄂(湖北长阳)交界地区，两系之间确实存在 笔石带的缺失(穆恩之, 1954) (图1). 这篇论文明确了孙 云铸先生(Sun，1943)提出的宜昌上升的真正地理范围 和时间跨度, 虽然宜昌上升的范围并不包括宜昌, 但是 仍不失其基本涵义, 因此一直为中国地质界所接受.

20世纪60 70年代, 穆恩之先生和他的学生们开始 系统研究五峰组中的笔石动物群, 其中的古地理部分 在1981年最早发表，其中“五峰期”的古地理图明显继
承了穆恩之(1954)的基本轮廓，但把五峰组部分缺失 的湘鄂交界地区改称为“湘鄂西隆起”(穆恩之等, 1981; Chen, 1984). Chen(1984)文中又首次把扬子区湘 鄂西隆起和奥陶纪末因南极冰盖凝聚造成的全球海平 面下降联系起来, 解释了它的控制因素. 2001年陈旭、 戎嘉余等按发表的优先律再度启用孙云铸先生(1943) 中“宜昌上升”一名，并圈定了它的分布范围和起始、 终结的时间. 戎嘉余、王怿等从2010年开始, 在宜昌 上升及其周缘进行奥陶-志留系界线上下地层的研究， 采集了多个剖面的五峰组和龙马溪组底部的笔石, 并 交由笔者之一(陈旭)鉴定，其中的主要剖面由王怿等 (2013)发表, 更进一步确定了宜昌上升的时限. 近年来 笔者等又获得了一些新的剖面和井下资料，并对过去 历年来已发表过的剖面中的笔石鉴定又作了进一步的 厘定，以此对“宜昌上升”的时空分布范围进行综合归 纳和总结.

近年来五峰组和龙马溪组底部黑色页岩在我国页 岩气开发中突显出特有的重要价值，因此本文将确切 地圈定宜昌上升过程中不同时期的圈层展布范围，指 出哪些范围龙马溪组黑色页岩发育完好，可以作为页 岩气勘探的优先选择区域; 也指出哪些范围是龙马溪 组黑色页岩的主要缺失区，需要在页岩气勘探布井时 加以避免. 本文与“黔渝地区志留系龙马溪组黑色页岩 的阶段性渐进展布模式”(陈旭等，2017)属于姊妹篇, 主要论及宜昌上升及其周缘龙马溪组黑色页岩的圈层 分布, 虽然其与黔渝模式有所不同, 但是这两个区域紧 密相连, 对页岩气勘探优选的区域相通, 更何况龙马溪

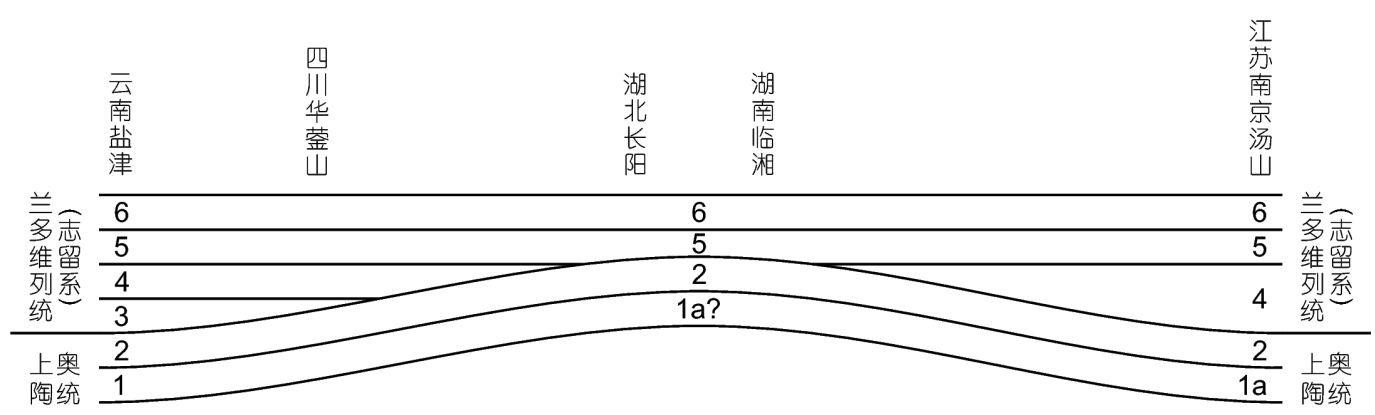

图 1 宜昌上升的时空展布

据穆恩之(1954). 1，Pleurograptus lui带(盐津层)；1a，三瘤虫带(汤头层)；2，Dicellograptus szechuanensis带(五峰页岩)；3，Glyptograptus persculptus带(龙马溪页岩最底部); 4, Akidograptus acuminatus带; 5, Orthograptus vesiculosus带; 6. Monograptus (Pristiograptus) cyphus带. 上 述生物带名称及序列已有较大修正, 详见本文介绍

1) 尹赞勋, 李星学. 1943. 南川地质旅行指南. 中国地质学会第十九次年会会后旅行指南 
组底部页岩气赋存的有利层段又是共同的，因此本文 将就此作进一步联系和对比. 本文29个主要剖面或井 下岩芯点的基础资料见附录 1 (网络版附录 1 , http:// earthcn.scichina.com). 同时, 为了节约篇幅, 本文中有 关五峰组-龙马溪组笔石带的名称仍使用陈旭等 $(2015$, 2017)以及本文附录1图1中的笔石带划分表中的代码, 而不逐一重复笔石带的全名. 但本文附录1中的剖面点 或井下资料, 仍附以笔石带全名, 以便同行们分别 引用.

\section{2 宜昌上升过程及含页岩气的有利圈层}

本文所圈定宜昌上升的范围是基于穆恩之(1954), 葛治洲等(1977)，陈旭等(2001)和王怿等(2013)的基础 之上, 补充了少数最近的资料, 以及对过去的已发表 资料进行再研究而产生的综合结果(图2).

位于宜昌上升最边缘的蓝色线条, 是奥陶系与志 留系连续沉积区与缺失龙马溪组底部LM1-LM2带的 环带区之间的界线. 换而言之, 此线之外是五峰组和龙 马溪组两套黑色页岩保存完整的地区, 也是两者之间 观音桥层保存完好的地区. 这个地区中, 位于宜昌上 升区以西的石柱漆辽河木厂沟(附录1剖面点19，简称 点19), 黔江沙坝庙林湾西(点20), 酉阳花田张家村北 (点26), 永顺石堤镇颗粒乡(点27), 永顺青坪镇(点28) 和慈利泊渡镇鱼米渡(点29)等地五峰组和龙马溪组底 部黑色页岩各笔石带发育完整, 其间夹有观音桥层, 奥 陶-志留系之间地层是连续沉积的. 陈旭等 $(2015,2017)$ 都已说明扬子区五峰组WF2-WF3, 以及龙马溪组 LM2-LM5/LM6下部是含页岩气最有利的层段, 因此 这一宜昌上升周缘含页岩气地层发育最完整的区域, 也是选择布井的有利地带.

位于图2蓝色与橙色线条之间的环状地带, 奥陶系 顶部至志留系底部, 即龙马溪组底部LM1-LM2带, 存 在不同程度的缺失. 自西向东的来风两河口(附录 1 井 下钻井点21)、长阳花桥(点15)和巴东思阳桥(点8)等 剖面为此提供了证据.

向内橙色与红色线条之间广阔地区, LM4-LM5覆 于五峰组(或临湘组)之上, LM1-LM3 普遍缺失. 区内大 量剖面点说明了这一明显的地层缺失, 它们包括建始 龙坪(附录1井下钻井点7)、恩施太阳河(点6)、宣恩高 罗(点22)、鹤峰太平乡官屋(点23)、五峰湾潭乡西(点
17)、石门龙池河(点 18 )、五峰城西 $1.5 \mathrm{~km}$ 处(点 13 )、 长阳大堰镇东北(点14)和宜都毛湖淌潘家湾(点16). 由 于这一位于宜昌上升中间部位的广阔地区普遍缺失 LM1-LM3, 甚至局部地点连LM4都已缺失, 损失了龙 马溪组底部黑色页岩中相当重要的一部分, 因此在这 一地区布井勘探龙马溪组黑色页岩中的页岩气需要格 外慎重.

位于宜昌上升东北部以五峰小河村(点12)为代表 的狭小封闭范围内, LM7直覆于临湘组之上, 五峰组、 观音桥层及龙马溪组LM1-LM6的黑色页岩全部缺失, 是宜昌上升的中心. 自临湘组之后, 该区直至LM7中部 才被海水重新淹没, 这一时间值也代表了宜昌上升的 终结. 因此以红色线条圈闭的这一窄小范围, 显然是 勘查龙马溪组黑色页岩中页岩气资源的禁区.

值得注意的是在宜昌上升的西南方向，彭水鹿角 镇(点24)和彭水洪渡大桥东端(点25)周缘的小范围之 内, 奥陶-志留系之间也存在着少量的地层缺失, 那里 的LM2-LM3 覆于五峰组之上. 再向西南方向即为黔中 古陆的影响范围, 在黔东北沿河甘溪、印江合水杨家 寨、思南英武溪、湄潭五里坡、湄潭牛场等地, 也都 存在着奥陶-志留系之间不同层位的缺失(陈旭等, 2001), 它们在LM4之下也都存在着一个短暂的沉积间 断. 这些地区与宜昌上升地区共同的地层缺失特征, 有 力地说明了宜昌上升和黔中古陆之间的紧密联系. 由 于受到广西运动的影响(陈旭等, 2014), 扬子地台南缘 在志留纪之初都存在过短暂的抬升, 只是在上扬子和 中扬子地区五峰组和龙马溪组的展布略有不同. 在上 扬子的黔渝地区, 龙马溪组为阶段性渐进展布(陈旭 等, 2017), 表现为自南而北龙马溪组黑色页岩分为 4 条 廊带; 而本文论及的中扬子湘鄂西地区, 则表现为以五 峰小河村为核心的宜昌上升的圈层展布(图3). 但是从 黔中古陆向东, 通过其上述黔东北的东延部分又和宜 昌上升连成了一体, 它们正好沿着中、上扬子地台的 南缘分布. 位于中、上扬子地台南缘的黔中古陆和宜 昌上升不断地向扬子海盆供给陆源碎屑, 从总体来看, 由南向北, 由近岸到远岸, 龙马溪组黑色页岩逐渐增 多, 愈向海盆中心黑色页岩相对海盆边缘更多, 因此 黑色页岩的顶界也就愈高. 在黔北桐梓-鄂西宜昌, 龙 马溪组LM6带上部, 典型的黑色页岩开始消失; 而至华 菳山-涪陵-巫溪-神龙架一线, 龙马溪组黑色页岩可高 至LM9带才消失. 由于扬子盆地南缘陆源碎屑的持 


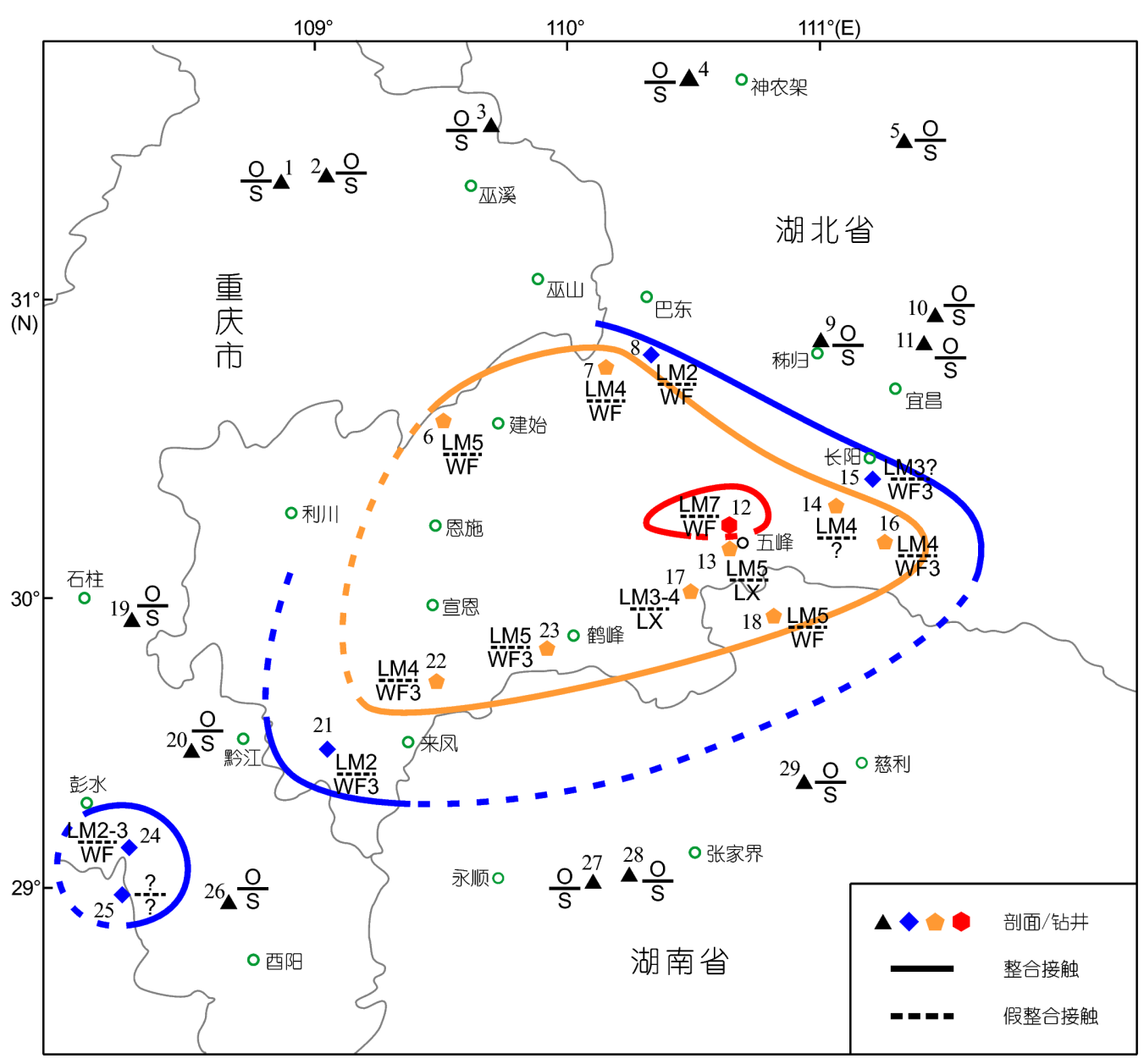

图 2 宜昌上升的范围及演变过程

剖面(或钻井)点: 1 , 重庆巫溪田坝; 2 , 重庆巫溪文峰镇以西; 3 , 重庆巫溪白鹿镇附近; 4 , 湖北神农架八角庙; 5 , 湖北保康马良坪; 6 , 湖北恩施太 阳河; 7, 湖北建始县龙坪; 8 , 湖北巴东思阳桥; 9 , 䄰归新滩龙马溪; 10 , 湖北宜昌王家湾; 11 , 湖北宜昌黄花场; 12 , 湖北五峰城北小河村; 13 , 湖 北五峰城西 $1.5 \mathrm{~km}$ 处; 14 , 湖北长阳大堰镇东北; 15 , 湖北长阳花桥; 16 , 湖北宜都毛湖淌潘家湾; 17 , 湖北五峰湾潭乡西; 18 , 湖南石门泥市龙池 河; 19, 重庆石柱漆辽河木厂沟; 20, 重庆黔江沙坝庙林湾西剖面; 21 , 湖北来凤两河口; 22, 湖北宣恩高罗; 23, 湖北鹤峰太平乡官屋; 24, 重庆彭 水鹿角镇; 25 , 重庆彭水洪渡大桥东端; 26 , 重庆西阳花园张家村北; 27 , 湖南永顺石堤镇颗粒乡附近; 28 , 湖南永顺青坪镇; 29 , 湖南慈利县泊渡 镇鱼米渡. 各点位地层发育详情, 请见附录1. LM, 龙马溪组; WF, 五峰组; LX, 临湘组

续、加速供给，抑制了龙马溪组较高层位黑色页岩的 发育，因此龙马溪组中LM2-LM5/LM6是产生页岩气 的主要层位.

陈旭等(2017)提出在黔中古陆以北的第4廊带, 即 綦江-华菳山廊带, 与郭册楼和张汉荣(2014)的五峰组龙马溪组优质泥页岩分布带一致。最近，罗超等 (2017)、梁峰等(2017)对长宁-威远页岩气田的研究, 更进一步表明长宁、威远和涪陵都是五峰组-龙马溪 组黑色页岩优质页岩气的勘探开发区。它和本文中说 明的宜昌上升周缘五峰组-龙马溪组连续沉积的三峡
地区，自然地汇聚并连成一体，扩大了五峰组-龙马溪 组下部黑色页岩勘探开发页岩气的有利地带.

\section{3 中、上扬子区在奥陶-志留系之交含页岩 气的有利层段}

近年来笔者之一(陈旭)在中国石油勘探开发研究 院、中国石化石油勘探开发研究院和国家地调局油气 中心的支持下, 从涪陵页岩气田开始, 对四川盆地及其 周缘30多口重要钻井的岩芯，运用笔石生物地层学的 


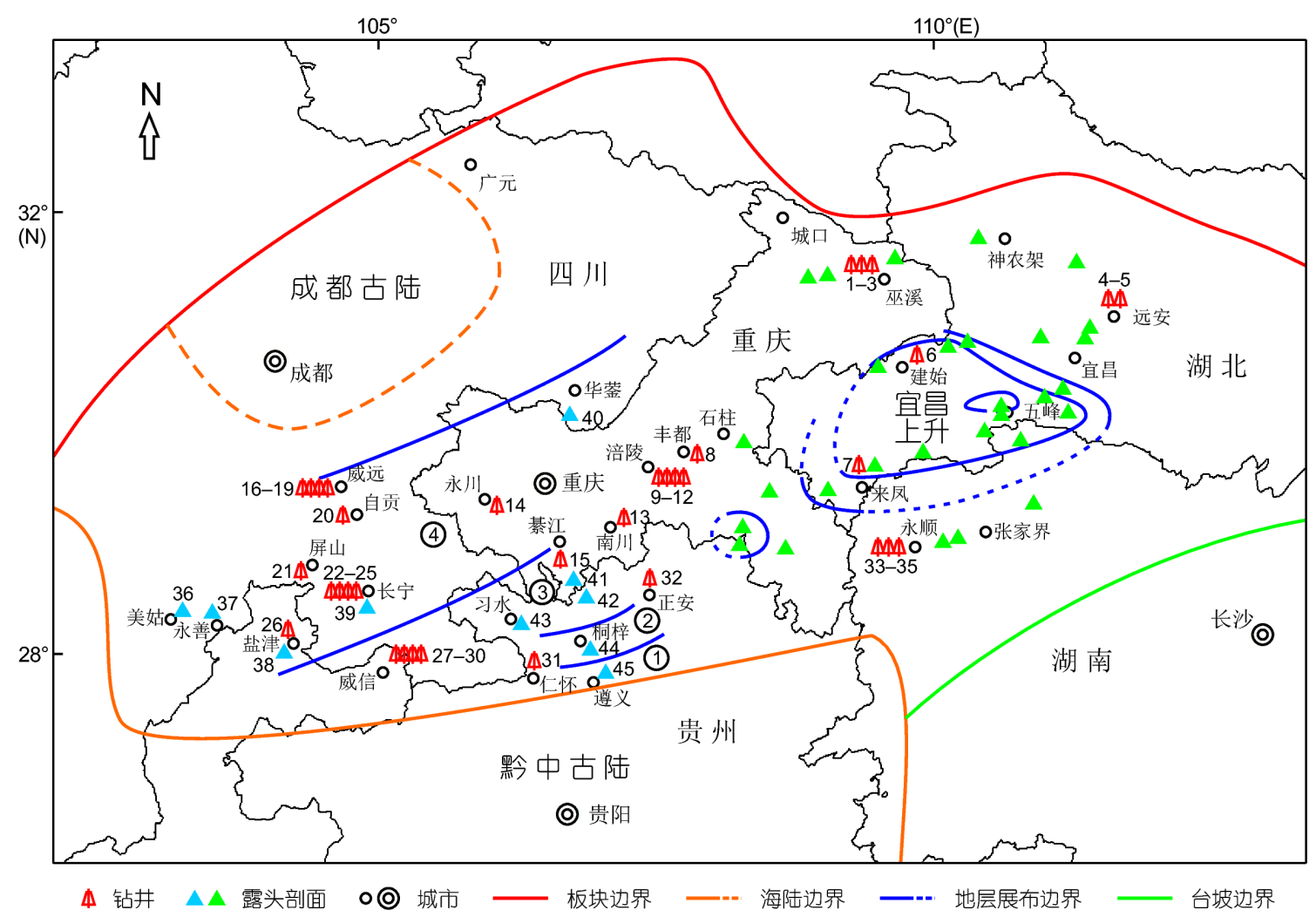

图 3 四川盆地及周缘龙马溪组黑色页岩的主要剖面及笔者等提供咨询的井位

钻井1-35为作者等近年来观察的相关钻井, 其井下笔石带的划分与对比情况, 与地表露头一致; 所有钻井点位位置仅为示意性. 绿色三角示宜 昌上升周缘主要剖面点位(见图2及附录1). 蓝色三角所代表的剖面分别为: 36 , 美姑地区; 37, 永善地区; 38 , 盐津老母城剖面; 39, 长宁双河剖 面; 40, 华菳山三百梯剖面; 41, 綦江观音桥剖面; 42, 桐梓韩家店剖面; 43, 习水习酒剖面; 44, 桐梓红花园剖面; 45, 遵义董公寺剖面. (1) 龙马溪 组仅发育LM5; (2) 龙马溪组发育LM4至LM6; (3) 龙马溪组发育LM1至LM6; (4) 龙马溪组发育LM1至LM7-8. 详见陈旭等 (2017)

方法进行划分、对比，并组成地层小组逐井提供咨询 报告(图3).

在此基础上，陈旭等 $(2015 ， 2017)$ 提出五峰组的 WF2(Dicellograptus complexus带)至WF3(Paraorthograptus pacificus带)和龙马溪组的LM2(Akidograptus ascensus 带)至LM5/LM6(Coronograptus cyphus带/Demirastrites triangulatus带), 是页岩气产出的主要烃源 岩层及储层. 上述五峰组至龙马溪组黑色页岩中笔石 带划分的框架，不但广为勘探部门所应用，而且已多 次被用于有关井下资料和区域性地层分析对比的论著 之中(聂海宽等，2016，2017；罗超等，2017；梁峰等， 2017). 而笔者等也从相关合作中获得大量井下岩芯和 地表露头剖面的资料，进而认识到龙马溪组黑色页岩 在上扬子黔渝地区的阶段渐进展布模式，和中扬子宜 昌上升范围内的圈层展布模式. 在这二者的控制范围
之内, 总有机碳(TOC)峰值和伽玛测井峰值均出现在 龙马溪组(LM2-LM5/LM6)的稳定层位之内, 在扬子区 展示了这种特定地层层位、总有机碳峰值和伽玛测井 峰值三位一体稳定出现的规律. 为了更好地说明这种 三位一体稳定出现的规律, 本文选取了涪陵地区、长 宁地区和来凤地区三口代表性的钻井，代表了在上、 中扬子区上述两种不同的黑色页岩展布范围内三位一 体的稳定组合, 而这种稳定组合和北非热页岩(Hot Shale)同期的组合具有很好的可对比性(图4).

图4中的三口井代表了两种类型: 涪陵地区的井代 表了龙马溪组黑色页岩中总有机碳(TOC)和伽玛测井 曲线高而持续稳定的纵向分布，而长宁和来风的两口 井却代表了 TOC和伽玛测井的峰值集中在LM2-LM5 范围内的局限分布. 根据我们在扬子区所观察的龙马 溪组井下和主要地表剖面(图3), 除涪陵地区之外, 其 


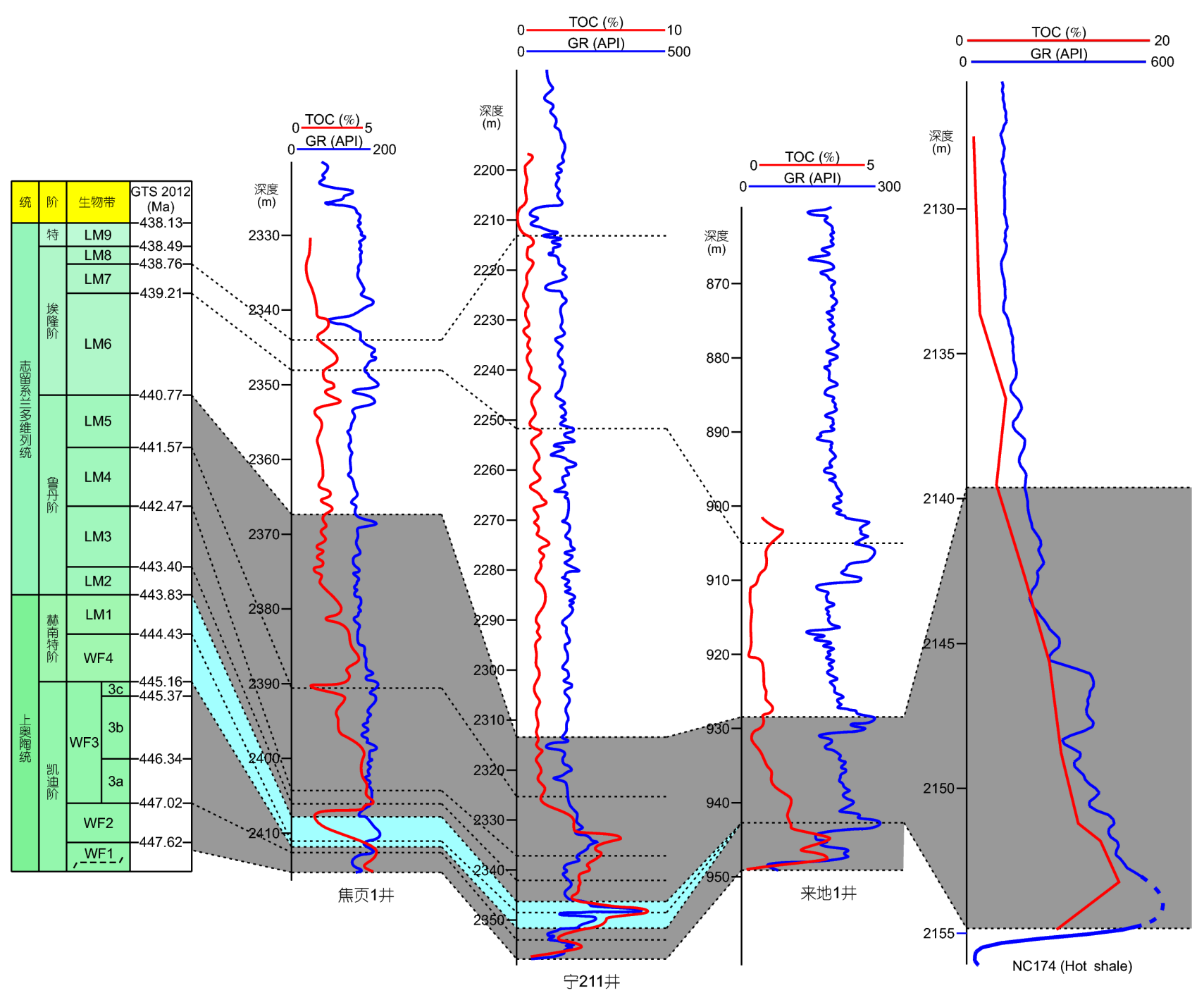

图 4 涪陵、长宁和来凤与北非热页岩井下同期总有机碳和伽玛测井曲线值的对比

焦页1井总有机碳(TOC)及自然伽玛(GR)曲线引自郭肜楼、刘若冰(2013), 宁211井引自罗超等(2017), 来地1井引自陈旭等(2015) $)^{2)}, \mathrm{NC174}$ 井引 自Lüning等(2000). 特, 特列奇阶

他地区均与长宁和来凤井下所代表的类型一致. 而这 一类型代表的大多数井位的三位一体的对应特征，和 北非热页岩中产出页岩气的诸多油气田一致，因为后 者总有机碳和伽玛测井的峰值也都出现在LM2至LM5 的局限层位中 (Lüning等，2000; 即本文图4北非 NC174井).

要查明井下伽玛测井峰值稳定分布在龙马溪组下 部LM2-LM5/LM6层位的原因，不得不和扬子区五峰
组和龙马溪组的地表露头中发育完好的斑脱岩层研究 相结合. 因为伽玛测井的峰值和火山活动喷发的火山 灰有关，也即反映在黑色页岩中夹含的 $\mathrm{K}$-斑脱岩层中. 火山喷发物质含有大量的营养元素，只要火山活动发 生后火山灰散落的面积足够大，火山灰溶解后就可以 为水体中的生物提供丰富的营养物质. Zhang等(2017) 证实了在太平洋贫营养物和叶绿素的海域内, 火山灰 的沉落和溶解会促进异养的菌类浮游植物富集, 并随

2) 陈旭, 王红岩, 赵群, 梁峰, 郭伟. 2015. 湖北来地1井五峰组和龙马溪组黑色页岩地层的划分与对比. 钻井咨询报告 
表 1 扬子区代表性剖面五峰组和龙马溪组中的主要斑脱岩层数

\begin{tabular}{|c|c|c|c|c|}
\hline & 宜昌黄花场-王家湾 & 宜昌界岭 & 神农架八角庙 & 桐梓红花园 \\
\hline $\begin{array}{c}\text { LM5-8 } \\
\text { (C. cyphus-S. sedgwickii 带) }\end{array}$ & & & 18 & \\
\hline $\begin{array}{c}\text { LM2-4 } \\
\text { (A. ascensus-C. vesiculosus 带) }\end{array}$ & 5 & & 6 & 6 \\
\hline \multicolumn{5}{|l|}{ 赫南特阶 } \\
\hline $\begin{array}{c}\text { WF2-3 } \\
\text { (D. complexus-P. pacificus 带) }\end{array}$ & 16 & 26 & & 16 \\
\hline
\end{tabular}

后带来浮游植物，以及包括微真核生物和大真核生物 的爆发. Hamme等(2010)曾记录了2008年8月在阿留申 群岛的火山爆发, 爆发数日后东北太平洋北极圈内低 等叶绿素明显增加，海域表层的 $p_{\mathrm{CO}_{2}}$ 值、 $\mathrm{pH}$ 值和莹光 反射也都指示了这一爆发. 现代海域中的例证指示了 地质历史中火山活动促进海水中有机质富集的相似过 程. 因此黑色页岩中自然伽马峰值与斑脱岩层的出现 所记录的火山活动，就很好地解释了有机质富集的一 种可能因素. 由于井下岩芯中往往难以获得质软层薄 的斑脱岩层，因此笔者等统计了苏文博等(2002)发表 的宜昌黄花场-王家湾、桐梓红花园五峰组和龙马溪 组下部的斑脱岩层，以及南京地质古生物研究所禁隽 轩团队在宜昌界岭和神农架八角庙等地五峰组和龙马 溪组中发现的主要斑脱岩层(表1).

表1表明了这些地区的斑脱岩层普遍发育于五峰 组WF2-WF3带和龙马溪组LM2-LM4带中，但在神农 架八角庙剖面龙马溪组的LM5-LM8层位中, 还出现了 较密集的斑脱岩层. Chikamoto等(2016)统计了现代太 平洋上Etna火山岛的火山喷发活动，发现火山灰沉落 物的数量与距火山的距离成反比, Olgun等(2013)对整 个太平洋热带火山物质喷发与距离的统计也是如此. 由此, 龙马溪组黑色页岩中的斑脱岩层在神农架相对 密集的出现，可能预示着在志留纪时期火山物质主要 源于扬子地块向秦岭的俯冲带之中。陈旭和戎嘉余 (1996)明确地展示了从扬子台地北缘特列奇期的黑色 页岩带-紫阳浊积岩带-火山碎屑岩带的台-坡-盆相带 模式，这和最近孟庆任(2017)展示的从扬子陆块-大巴 山构造带-南秦岭构造带的展布是一致的, 这也即其推 测的外来地块和扬子陆块之间的构造带接合部位. 因 此扬子地台上由北而南, 夹含在五峰组-龙马溪组黑色 页岩中由多渐少的斑脱岩中的火山物质, 就可能源自
这一构造带的接合部.

龙马溪组黑色页岩中的总有机碳峰值集中于 LM2-LM5/LM6层位中，其原因之一固然是因为在鲁 丹-埃隆期扬子地台上黑色页岩广泛发育，这一时期华 南的岩相变化主要由于全球海平面上升起主导作用. 至LM6时期后因广西运动波及扬子地台，导致地区性 的抬升起了主导作用，才使扬子地台南缘的陆源碎屑 物散布到了扬子盆地的中心位置，从而导致扬子盆地 中心部位黑色页岩消失, 或夹含粉砂岩和砂岩, 降低 了总有机碳的含量. 而另一方面，鲁丹-埃隆期龙马溪 组下部总有机碳含量的富集, 也与全球范围内由冰室 效应转为温室效应的宏观古气候背景和相应的大洋环 流模式的转换有关. Brenchley等(1995)曾提出一个奥 陶纪末-志留纪初的大洋循环模式(图5), 它虽然简化 了这一过程，但仍不失为一个通用模式(Harper等, 2014).

赫南特期之前全球处于温室效应时期，海洋普遍 是一种海水分层模式，暖盐的深层水集中在盆地的底 层. 扬子盆地的五峰组沉积时期由于华夏古陆的扩展 围限, 海盆处于一个半封闭的大海湾式的滞流盆地环 境条件之下, 底层水缺氧, 有机质富集保存. 这种海水 分层模式虽然有它在封闭环境下的特殊性，但仍不失 在全球温室效应条件下的普遍性. 只是因为这种封闭 和滞流条件, 使五峰组沉积物的有机质更加富集, 从 而为页岩气的产生提供了有利条件. 赫南特期南极冰 盖凝聚，全球海平面下降，极区大量的冷水潜入低纬 度海洋的深层，一度打破了海水分层模式. 冰期结束 后，由于南极冰盖迅速消融，全球海洋又恢复了海水 分层模式，而且伴随着全球海平面的上升，大量的有 机质扩展到台地上并沉积下来. 因此，扬子地台上龙 马溪组下部的黑色页岩也是全球志留纪早期黑色页岩 

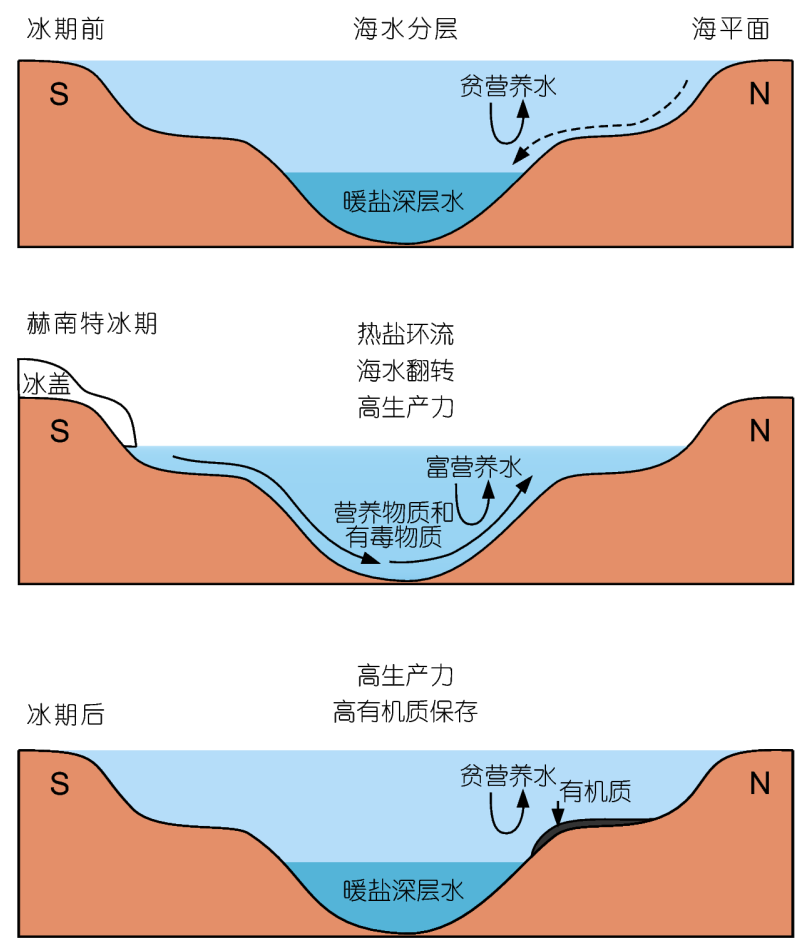

图 5 奥陶纪-志留纪之交大洋循环模式及古生产力演变模式 修改自Brenchley等(1995)

事件的组成部分. 但是非洲北部阿尔及利亚和利比亚 等地志留纪早期黑色页岩生成的油气田, 其生成的环 境更具特殊性. 因为赫南特期冰盖正位于非洲西北部, 冰盖在凝聚和消融过程中移动产生的刨蚀作用，在北 非克拉通基底上形成巨大的凹坑，志留纪初海平面上 升，海水灌入坑内形成封闭的小盆地，更利于有机质 的富集，这些彼此孤立的小盆地就成为了当前北非主 要的油气田(Lüning等, 2000). 扬子盆地虽然不具备北 非这种特殊的古地形条件, 但发生志留纪初全球黑色 页岩事件的基本条件却是共同的.

致谢感谢评审专家的意见和建议. 甄勇媇的工作已经 得到新南威尔士州地质调查所所长批准.

\section{参考文献}

陈旭, 牀隽轩, 陈清, 唐兰, 侯旭东. 2014. 论广西运动的进程. 中国科

学: 地球科学, 44: 842-850

陈旭, 焚隽轩, 王文卉, 王红岩, 聂海宽, 石学文, 文治东, 陈冬阳, 李

文杰. 2017. 黔渝地区志留系龙马溪组黑色笔石页岩的阶段性渐
进展布模式. 中国科学: 地球科学, 47: 720-732

陈旭, 樊隽轩, 张元动, 王红岩, 陈清, 王文卉, 梁峰, 郭伟, 赵群, 聂海 宽, 文治东, 孙宗元. 2015. 五峰组及龙马溪组黑色页岩在扬子覆 盖区内的划分与圈定. 地层学杂志, 39: 351-358

陈旭, 戎嘉余, 周志毅, 张元动, 詹仁斌, 刘建波, 㚞隽轩. 2001. 上扬 子区奥陶-志留纪之交的黔中隆起和宜昌上升. 科学通报，46: 1052-1056

陈旭, 戎嘉余. 1996. 中国扬子区兰多维列统特列奇阶及其与英国的 对比. 北京: 科学出版社. 162

焚隽轩, Melchin M J, 陈旭, 王怿, 张元动, 陈清, 迟昭利, 陈峰. 2012. 华南奥陶-志留系龙马溪组黑色笔石页岩的生物地层学. 中国科 学: 地球科学, 42: 130-139

葛治洲, 戎嘉余, 杨学长, 刘耕武, 倪寓南, 董得源, 伍鸿基. 1977. 西 南地区志留系十条剖面资料. 地层古生物, 8: 92-111

郭肜楼, 刘若冰. 2013. 复杂构造区高演化程度海相页岩气勘探突破 的启示一一四川盆地东部盆缘JY1井为例. 天然气地球科学, 24: 643-651

郭肜楼, 张汉荣. 2014. 四川盆地焦石坝页岩气田形成与富集高产模 式. 石油勘探与开发, 41: 28-36

梁峰, 王红岩, 拜文华, 郭伟, 赵群, 孙莎莎, 张琴, 武瑾, 马超, 雷治安. 2017. 川南地区五峰组-龙马溪组页岩笔石带对比及沉积特征. 天 然气工业, 37: 20-26

罗超, 王兰生, 石学文, 张鉴, 吴伟, 赵圣贤, 张成林, 杨雅茜. 2017. 长 宁页岩气田宁 211 井五峰组-龙马溪组生物地层. 地层学杂志, 41: $142-152$

孟庆任. 2017. 秦岭的由来. 中国科学: 地球科学, 47: 412-420

穆恩之, 李积金, 葛梅铎, 陈旭, 林尧坤, 倪寓南. 1993. 华中区上奥陶 统笔石. 中国古生物志, 新乙种第29号. 北京: 科学出版社. 393

穆恩之, 李积金, 葛梅铎, 陈旭, 倪寓南, 林尧坤. 1981. 华中区晚奥陶 世古地理图及其说明书. 地层学杂志, 5: 165-170

穆恩之. 1950. 关于笔石的演化和分类. 地质论评, 14: 171-183

穆恩之. 1954. 论五峰页岩. 古生物学报, 2: 153-170

聂海宽, 金之钧, 边瑞康, 杜伟. 2016. 四川盆地及其周缘上奥陶统五 峰组-下志留统龙马溪组页岩气“源-盖控藏”富集. 石油学报, 37 : $557-571$

聂海宽, 金之钧, 马鍂, 刘忠宝, 林拓, 杨振恒. 2017. 四川盆地及邻区 上奥陶统五峰组-下志留统龙马溪组底部笔石带及沉积特征. 石 油学报, 38: 160-174

苏文博, 何龙清, 王永标, 龚淑云, 周湖云. 2002. 华南奥陶-志留系五 峰组及龙马溪组底部斑脱岩与高分辨率综合地层. 中国科学 $\mathrm{D}$ 辑: 地球科学, 32: 207-219

汪啸风, 项礼文, 倪世钊, 曾庆俥, 徐光洪, 周天梅, 赖才根, 李志宏. 1987. 长江三峡地区生物地层学(2), 早古生代分册. 北京: 地质出 版社. 641

王怿, 戎嘉余, 詹仁斌, 黄冰, 吴荣昌, 王光旭. 2013. 鄂西南奥陶系志留系交界地层研究兼论宜昌上升. 地层学杂志, 37: 264-274 
王钰. 1945. 三峡式下部古生代地层之分层. 地质论评, 10: 9-14

尹赞勋. 1943. 关于龙马溪页岩. 地质论评, 8: 1-8

Brenchley P J, Carden G A F, Marshall J D. 1995. Environmental changes associated with the first strike of the Late Ordovician mass extinction. Modern Geol, 20: 69-82

Chen X. 1984. Influence of the Late Ordovician glaciation on basin configuration of the Yangtze Platform in China. Lethaia, 17: 51-59

Chikamoto Y, Mochizuki T, Timmermann A, Kimoto M, Watanabe M. 2016. Potential tropical Atlantic impacts on Pacific decadal climate trends. Geophys Res Lett, 43: 7143-7151

Hamme R C, Webley P W, Crawford W R, Whitney F A, DeGrandpre M D, Emerson S R, Eriksen C C, Giesbrecht K E, Gower J F R, Kavanaugh M T, Peña M A, Sabine C L, Batten S D, Coogan L A, Grundle D S, Lockwood D. 2010. Volcanic ash fuels anomalous plankton bloom in subarctic northeast Pacific. Geophys Res Lett, 37: L19604

Harper D A T, Hammarlund E U, Rasmussen C M Ø. 2014. End Ordovician extinctions: A coincidence of causes. Gondwana Res, 25: 1294-1307

Lee J S, Chao Y T. 1924. Geology of the Gorge District of the Yangtze (from Ichang to Tzekuei) with special reference to the development of the Gorges. Bull Geol Soc China, 3: 351-391

Lüning S, Craig J, Loydell D K, Štorch P, Fitches B. 2000. Lower Silurian 'hot shales' in North Africa and Arabia: Regional distribution and depositional model. Earth-Sci Rev, 49: 121-200

Mu A T. 1945. Graptolite fauna from the Wufeng Shale. Bull Geol Soc China, 25: 201-209

Olgun N, Duggen S, Andronico D, Kutterolf S, Croot P L, Giammanco S, Censi P, Randazzo L. 2013. Possible impacts of volcanic ash emissions of Mount Etna on the primary productivity in the oligotrophic Mediterranean Sea: Results from nutrient-release experiments in seawater. Mar Chem, 152: 32-42

Sun Y C. 1943. Bases of the chronological classification with special reference to the Palaeozoic stratigraphy of China. Bull Geol Soc China, 23: 35-56

Yin T H, Mu A T. 1945. Lower Silurian graptolites from Tungtzu. Bull Geol Soc China, XXV: 211-219

Zhang R, Jiang T, Tian Y, Xie S C, Zhou L, Li Q, Jiao N Z. 2017. Volcanic ash stimulates growth of marine autotrophic and heterotrophic microorganisms. Geology, 45: 679-682

(责任编委: 朱茂炎) 